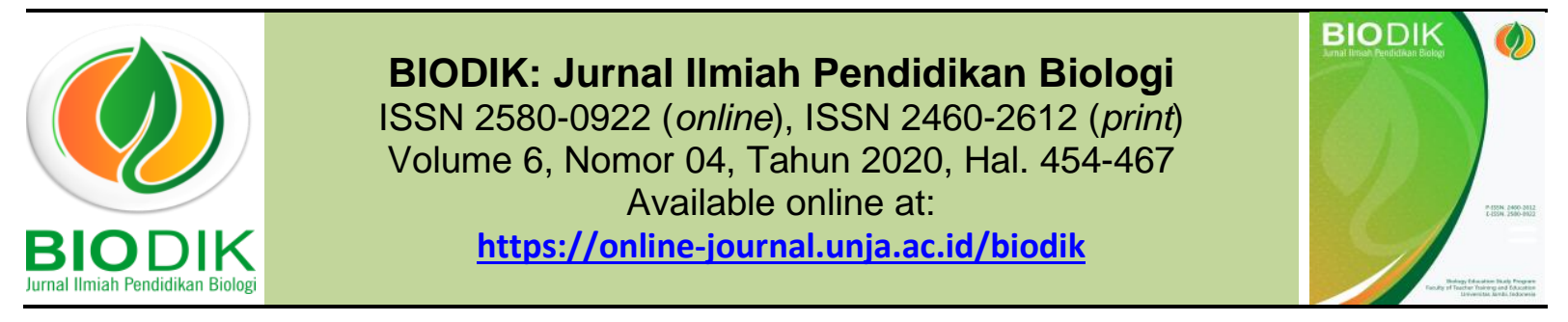

Research Article

open access

\title{
Analisis dan Rekonstruksi Lembar Kerja Siswa Materi Spermatophyta Dengan menerapkan Analisis Fenetik
}

\section{(Analysis and Reconstruction of Practical Work Spermatophyta Material By applying Phenetic Analysis)}

Eliya Mei Sisri*, Sri Anggraeni, Bambang Supriatno

Universitas Pendidikan Indonesia

Jl. Dr. Setiabudi No.229, Isola, Kec. Sukasari, Kota Bandung, Jawa Barat 40154

*Coressponding Author: eliyameisisri@gmail.com

\begin{tabular}{|c|c|}
\hline Informasi Artikel & ABSTRACT \\
\hline $\begin{array}{l}\text { Submit: } 03-06-2020 \\
\text { Diterima: } 19-10-2020 \\
\text { Dipublikasikan: } 18-12-2020\end{array}$ & $\begin{array}{l}\text { Competence in spermatophyta material can be achieved through practicum methods. } \\
\text { The practicum student worksheet also determines the achievement of the practicum } \\
\text { activity objectives, so it is necessary to analyze the suitability of the components in } \\
\text { the worksheet. The purpose of this study is to get a picture of the problems that exist } \\
\text { in LKS through the activity of analysis and trials, the results of the analysis and trials } \\
\text { are used as a basis for LKS reconstruction. This research uses a descriptive } \\
\text { qualitative approach. The population in this study were all high school biology } \\
\text { worksheets in class X with spermatophyta material based on the } 2013 \text { curriculum and } \\
\text { KTSP used by students in schools. Samples were taken by simple random sampling. } \\
\text { The samples studied were three } 2013 \text { curriculum LKS and three KTSP LKS. The } \\
\text { analysis was carried out on } 6 \text { LKS of spermatophyta material using practical analysis } \\
\text { instruments. The findings of the problem on LPS of spermatophyta were conceptual, } \\
\text { practical and knowledge construction. In terms of the percentage of suitability of the } \\
\text { SBC LKS with the highest parameters is } 72 \% \text { and the lowest is } 44 \% \text {, while the } \\
\text { percentage of conformity of the } 2013 \text { LKS K is the highest } 64 \% \text { and the lowest is } \\
36 \% \text {. This finding suggests that the worksheets that are used are not adapted to } \\
\text { changes in KD demands as the curriculum changes. From the findings, the LKS in } \\
\text { spermatophyta material needs to be reconstructed in terms of conceptual, practical } \\
\text { and knowledge construction. The spermatophyta LKS reconstruction uses a phenetic } \\
\text { analysis along with the demands of the } 2013 \text { curriculum. } \\
\text { Keywords: : Analysis, Practical Work, Spermatophyta, Phenetic Analysis. }\end{array}$ \\
\hline Penerbit & ABSTRAK \\
\hline $\begin{array}{l}\text { Program Studi Pendidikan } \\
\text { Biologi, Fakultas Keguruan dan } \\
\text { IImu Pendidikan, Universitas } \\
\text { Jambi }\end{array}$ & $\begin{array}{l}\text { Kompetensi pada materi spermatophyta dapat dicapai melalui metode praktikum. } \\
\text { LKS praktikum turut menentukan pencapaian tujuan kegiatan praktikum, sehingga } \\
\text { perlu analisis kesesuaian komponen yang ada dalam LKS. Tujuan penelitian ini untuk } \\
\text { mendapatkan gambaran permasalahan yang ada pada LKS melalui kegitan analisis } \\
\text { dan uji coba, hasil analisis dan uji coba dijadikan sebagai dasar rekonstruksi LKS. } \\
\text { Penelitian ini menggunakan pendekatan kualitatif deskriptif. Populasi dalam } \\
\text { penelitian ini adalah seluruh LKS Biologi SMA kelas X materi spermatophyta } \\
\text { berbasis Kurikulum } 2013 \text { dan KTSP yang digunakan oleh siswa di sekolah. Sampel } \\
\text { diambil secara simple random sampling. Sampel yang diteliti adalah tiga LKS } \\
\text { kurikulum } 2013 \text { dan tiga LKS KTSP. Analisis dilakukan pada } 6 \text { LKS materi } \\
\text { spermatophyta ini menggunakan instrumen analisis kegiatan praktikum.Temuan } \\
\text { permasalahan pada LKS spermatophyta yaitu terkait konseptual, praktikal dan } \\
\text { kontruksi pengetahuan. Secara persentase kesesuaian LKS KTSP dengan } \\
\text { parameter yang tertinggi adalalah 72\% dan terendah 44\%, sedangkan persentase } \\
\text { kesesuaian LKS K } 2013 \text { yang tertinggi } 64 \% \text { dan yang terendah 36\%. Temuan ini } \\
\text { mengisyaratkan bahwa LKS yang dipakai tidak disesuaikan dengan perubahan }\end{array}$ \\
\hline
\end{tabular}


tuntutan KD seiring perubahan kurikulum. Dari hasil temuan, maka LKS pada materi spermatophyta perlu direkonstruksi terkait konseptual,praktikal dan maupun konstruksi pengetahuan. Rekonstruksi LKS spermatophyta ini menerapkan analisis fenetik seiring dengan tuntutan kurikulum 2013.

Katakunci: Analisis, Lembaran Kerja Siswa (LKS), Spermatophyta, Analisis fenetik.

This BIODIK : Jurnal IImiah Pendidikan Biologi is licensed under a CC BY-NC-SA (Creative Commons Attribution-ShareAlike 4.0 International License)

\section{PENDAHULUAN}

Salah satu keterampilan yang dapat dikembangkan untuk mempersiapkan siswa abad 21 adalah Keterampilan Proses Saint (KPS). KPS merupakan keterampilan dasar yang harus dikembangkan dan dilatihkan agar peserta didik mampu menggunakan metode ilmiah. Pendekatan keterampilan proses dapat digunakan untuk memahami konsep, bekerja ilmiah, mengembangkan ilmu, mempertahankan hidup di masyarakat dan di alam (N. R. dan A. R. Rustaman, 2003). Bekerja ilmiah tidak sekedar mengumpulkan fakta, teori, atau proses mental dan keterampilan manipulatif, namun diharapkan dapat memperoleh pengetahuan baru atau mengembangkan pengetahuan yang telah dimiliki. Keterampilan proses saint dapat membuat peserta didik berfikir kritis, bernalar, dan bersikap ilmiah, dimana kemampuan-kemampuan ini diperlukan dalam bekerja ilmiah. Penerapan keterampilan proses sains dalam pembelajaran biologi dapat diintegrasikan ke dalam kegiatan praktikum siswa. Namun dibutuhkan strategi pembelajaran khusus agar keterampilan proses terus berkembang. Salah satunya adalah strategi pembelajaran inkuiri (Yusni astuti, 2013). Inkuiri merupakan suatu proses bagi siswa untuk memecahkan masalah, merencanakan, melakukan eksperimen, mengumpulkan data dam mengambil kesimpulan (N. Y. Rustaman, 2005).

Lembaran Kegiatan Siswa (LKS) sebagai panduan praktikum pada umumnya dirancang secara khusus agar peserta didik dapat mengembangkan aktivitas belajar, memperoleh fakta dari hasil pengamatan. Tantangan dalam tugas praktek adalah kemampuan membuat hubungan antara apa yang dilihat dengan gagagasan yang dimiliki sebelumnya. Kerja praktek yang dilakukan siswa disekolah bertujuan untuk mengajarkan siswa melakukan penyelidikan ilmiah, namun pendekatan ini memiliki beberapa kesulitan; (1) Kurangnya pengalaman, peralatan, waktu siswa; (2) pengukuran/ pengamatan tidak lengkap, salah, sehingga data tidak konsisten dengan kesimpulan; (3) sulit menyimpulkan hubungan antar data sehingga sering menyimpulkan apa yang siswa duga bukan dari data (Millar, 2004). Para guru percaya bahwa melalui kegiatan praktikum dapat mengembangkan pengetahuan prosedural, konseptual, dan meningkatkan minat sains siswa (Sani, 2014). Pembelajaran langsung dan kontekstual merupakan karakteristik pembelajaran biologi dalam menggungkap fenomena yang ada di lingkungan (Aisya et al., 2016). Pengetahuan konseptual memuat ide atau gagasan dalam suatu disiplin ilmu yang memungkinkan orang untuk mengklasifikasikan suatu objek atau mengelompokan 
atau mengklarifikasikan berbagai objek. Pengetahuan prosedural merupakan pengetahuan mengenai bagaimana melakukan sesuatu. Pengetahuan prosedural sering mengambil bentuk dari suatu rangkaian langkah-langkah yang akan diikuti. Pengetahuan prosedural memiliki peranan penting dalam penataan konsep dan memperoleh pengetahuan deklaratif (Yılmaz \& Yalçın, 2012).

Konsep-konsep biologi sebagai salah satu ilmu sains akan semakin mudah diingat oleh para siswa melalui kegitan eksperimen, karena siswa benar-benar melakukan secara langsung (Education, 2010). Pelajaran biologi berkaitan dengan cara mencari tahu dan memahami tentang alam secara sistematis sehingga siswa dituntut untuk dapat berfikir kritis dan kreatif (Sadikin \& hakim, 2015) Kegiatan praktikum dapat menunjang penguasaan konsep atau materi pelajaran secara verifikatif atau secara penemuan (N. R. dan A. R. Rustaman, 2003). Panduan praktikum merupakan salah satu dukungan yang diperlukan untuk implementasi kegiatan praktikum (Niteni, 2020) sehingga tujuan pembelajaran bisa tercapai dan memperkecil resiko kecelakaan. Panduan praktikum perlu dirancang secara hati-hati agar dapat dievaluasi sejauh mana siswa bereksplorasi pada kegiatan praktikum (The Society for Biology, 2010).

Peran LKS sangat besar dalam pembelajaran karena menggambarkan langkahlangkah proses ilmiah yang lengkap mulai dari perumusan masalah sampai menemukan masalah baru. Jika siswa terbiasa menggunakan kaidah proses ilmiah yang benar, maka semua ranah kognitif, afektif, psikomotorik dan keterampilan sosial diharapkan akan berkembang. LKS yang dipergunakan siswa dalam kegiatan praktikum biologi ada yang disusun oleh guru yang bersangkutan dan ada yang dari penerbit tertentu. LKS harus memuat petunjuk langkah-langkah untuk mengerjakan hal tertentu. Rancangan langkah-langkah ini haruslah tepat sehingga aktivitas praktikum dapat membawa peserta didik sampai pada objek/even yang relevan (Supriatno \& Si, 2018). Seyogyanya panduan praktikum LKS mencerminkan hal-hal berikut: (1) Apa tujuan yang akan dipelajari siswa;(2) Apa yang harus dilakukan siswa; (3) Dapat mengukur apa sebenarnya yang dilakukan siswa ketika belajar;(4) Apa yang dipelajari siswa. Melalui kerja praktek siswa dapat membuat tautan hasil observasi dengan pengetahuan yang sudah mereka ketahui guna meningkatkan pengetahuan ilmiah (Millar \& Abrahams, 2009).

Apakah LKS yang saat ini digunakan di SMA sudah memberikan pengalaman belajar bagi siswa untuk melakukan proses proses saint yang runtut, benar dan mampu mengajak siswa membangun konsep? Penelitian yang dilakukan Supriatno (2009) menunjukkan bahwa (1) Ketidak selarasan antara tujuan kerja dengan langkah kerja bahkan menimbulkan miskonsepsi; (2) konten tidak sesuai; (3) kurangnya atau tidak mengembangkan proses berfikir; (4) knowledge claim/kompetensi yang dicapai tidak jelas/relevan (Supriatno \& Si, 2018). Pekerjaan laboratorium sains membuat siswa frustasi atau tidak berarti karena siswa merasa kesulitan melihat interaksi apa yang mereka ketahui dengan hasil percobaan (Novak \& Gowin, 1983).Oleh karena itu dalam penelitian ini akan dilakukan analisis setiap komponen penyusun LKS agar dapat membantu siswa dalam kegiatan laboratorium.

\section{Sisri, $\mathbf{d k k}$}


Dalam analisis ini saya memilih judul Spermatophyta karena praktikum ini dapat dilakukan dalam keadaan sekolah yang sederhana sekalipun, praktikum ini dapat dilakukan tanpa peralatan mahal, bahan tidak sulit didapat, bahkan praktikum ini juga tidak membutuhkan bangunan labor yang khusus. Disamping itu siswa masih mengalami miskonsepsi pada konsep keterbukaan biji, perbungaan, pertulangan daun dan manfaat tumbuhan (Faturrohman, 2016). Temuan lain juga menyatakan bahwa LKS yang sudah ada dari buku paket maupun sumber lain kurang cocok dengan kondisi sekolah(Astuti, 2015)

Pada kurikulum 2013 kompetensi dasar (KD) yang harus dikuasai oleh siswa kelas X SMA pada materi "Tumbuhan, adalah KD 3.8 Mengelompokkan tumbuhan ke dalam divisio berdasarkan ciri-ciri umum, serta mengaitkan peranannya dalan kehidupan, dan KD 4.8 Menyajikan laporan hasil pengamatan dan analisis fenetik dan filogenetik tumbuhan serta peranannnya dalam kehidupan" tuntutan KD ini dapat diartikan bahwa siswa mampu menerapkan prinsip klasifikasi untuk menggolongkan tumbuhan ke dalam divisionya berdasarkan pengamatan morfologi dan menyusun fenogram dari analisis fenetik tumbuhan serta megaitkan peranannya dalam kelangsungan kehidupan di bumi (Kemendikbud, 2016). Untuk memenuhi tuntutan KD, maka LKS sebagai alat bantu pada proses praktikum harus memuat langkahlangkah pengamatan ciri-ciri morfologi dan langkah-langkah pembuatan fenogram yang mudah dipahamami dan dilakukan oleh siswa dalam kegiatan praktikum. Kegiatan pembelajaran dengan menggunakan penugasan fenetik melalui LKS, memberikan hal-hal yang menunjang pada naiknya penguasaan konsep siswa pada konsep keanekaragaman hayati khususnya tumbuhan biji (Hidayat et al., 2015). Cara kerja klasifikasi dengan analisis fenetik yaitu dengan menentukan unit taksonomi operasional (OTU), menganalisis karakter sebagai karakteristik biner, dan selanjutnya pembentukan kelompok berdasarkan nilai-nilai kesamaan (AbdelHameed et al., 2015). Fenetik menaksir hubungan evolusi berdasarkan kepemilikan karakter atau ciri yang sama (overall similarity) dari anggota-anggota suatu kelompok. Terdapat lima langkah dalam melakukan analisis fenetik. (1) menyeleksi organisme yang akan dianalisis (disebut Taksa); (2) menentukan tingkat kesamaan antara pasangan taksa dengan menghitung koefisien kesamaan; (3) menyusun koefisien kesamaan di atas ke dalam bentuk matriks kesamaan; (4) nilai-nilai kesamaan dalam matriks kesamaan selanjutnya dibuat klastering; (5) merekonstruksi pohon kekerabatan fenetik (biasa disebut Fenogram) (Hidayat, 2017).

Berdasarkan hasil observasi di sekolah KD 3.8 dan KD 4.8 ini dipelajari melalui kegiatan praktikum. Melalui kegiatan praktikum siswa dapat memanipulasi dan mengamati benda secara nyata sehingga pembelajaran menjadi menarik (Abrahams \& Millar, 2008). Dalam kegiatan praktikum siswa menggunakan LKS sebagai petunjuk melakukan identifikasi ciri-ciri tumbuhan. Untuk mengetahui keefektifan kegiatan praktikum perlu dilakukan analisis terhadap LKS yang digunakan di sekolah. Dimana hasil analisis tersebut nantinya akan digunakan sebagai tolak ukur dalam melakukan rekonstruksi. Hasil rekonstruksi ini diharapkan dapat membuat kegiatan praktikum berjalan lebih baik dan menutun siswa untuk mengkonstruksi 
pengetahuan sendiri dari apa yang diamatinya secara langsung. Atas pertimbangan itulah saya merasa perlu untuk menganalis dan menguji coba LKS pada materi spermatophyta.

Tujuan penelitian ini untuk mendeskripsikan dan menganalisis setiap komponen penyusun LKS pada materi spermatophyta dengan menggunakan instrumen analisis kegiatan laboratorium dan melakukan uji coba kegiatan praktikum mengikuti langkahlangkah kerja yang ada pada LKS. Hasil analisis dan uji coba inilah yang akan digunakan sebagai dasar rekonstruksi LKS pada materi spermatophyta. Harapannya LKS hasil rekonstruksi ini dapat memenuhi tuntutan KD dan dapat melatih siswa melakukan metode ilmiah.

\section{METODE PENELITIAN}

Penelitian ini mengunakan pendekatan kualitatif untuk memeriksa permasalahan komponen penyusun LKS praktikum biologi pada materi spermatophyta di tingkat sekolah menengah atas (SMA). Penelitian ini tergolong penelitian deskriptif dikarenakan memberikan gambaran permasalahan pada komponen penyusun LKS ptakikum. Populasi dalam penelitian ini adalah seluruh LKS biologi SMA kelas $X$ yang membahas materi spermatophyta berbasis kurikulum 2013 dan KTSP yang digunakan oleh siswa SMA di sekolah. Sampel diambil secara simple random sampling. Sampel terdiri dari enam LKS yang dikategorikan menurut kurikulumnya yaitu 3 LKS kurikulum 2013 dan 3 LKS KTSP. Pengkodean LKS yaitu LKS 1, LKS 2, LKS 3 untuk LKS kurukulum 2013 dan LKS 4, LKS 5, LKS 6 untuk LKS KTSP. Metode pengumpulan data dalam penelitian ini adalah dengan melakukan analisis LKS menggunakan instrumen analisis kegiatan laboratorium serta uji coba terhadap LKS yang dipilih sebagai sampel. Analisis dilakukan dengan cara menjudgement setiap komponen penyusun LKS menggunakan setiap point parameter yang ada pada instrumen analisis kegiatan laboratorium. Analisis dalam instrumen meliputi (1) kesesuaian secara konseptual; (2) kesesuaian secara praktikal; (3) kesesuaian konstruksi pengetahuan. Uji coba praktikum dilakukan dengan langkah-langkah yang ada pada LKS. Setelah selesai analisis dan uji coba, dilakukan rekonstruksi terhadap LKS.

Tabel 1. Instrumen Analisis Kegiatan Laboratorium

\begin{tabular}{lll}
\hline No & Aspek & Parameter \\
\hline 1 & Konseptual & Apakah konten sesuai dengan Kompetensis dasar (KD). \\
\hline & Apakah kompetensi yang dikembangkan LKS sesuai dengan KD. \\
\hline & Apakah judul praktikum sesuai dengan langkah-langkah kerja. \\
\hline & Apakah tujuan praktikum sesuai dengan langkah-langkah kerja. \\
\hline 2 & Praktikal & Apakah kegiatan praktikum sesuai dengan tingkat kognitif siswa SMA. \\
\hline
\end{tabular}

\section{Sisri, $d k k$}




\begin{tabular}{|c|c|}
\hline & Apakah bahan yang digunakan mudah didapat siswa. \\
\hline & Apakah langkah kerja sudah disusun terstruktur. \\
\hline & Apakah langkah kerja dapat dieksekusi tanpa kesulitan. \\
\hline & Apakah objek/fenomena muncul dalam pengamatan. \\
\hline & Apakah objek/fenomena mudah untuk diamati. \\
\hline & Apakah ada perekaman data. \\
\hline & Bagaimana bentuk perekaman objek/fenomena. \\
\hline & Apakah objek fenomena relevan dengan judul/tujuan. \\
\hline & Apakah ada alokasi waktu untuk kegiatan praktikum. \\
\hline & Apakah ada petunjuk safety lab. \\
\hline & Apakah prosedur petunjuk safety labnya tepat. \\
\hline $3 \quad$ Konstruksi & Apakah pertanyaan praktikum tidak dapat dijawab tanpa praktikum. \\
\hline Pengetahuan & \\
\hline & Apakah pertanyaan praktikum menanyakan karakter fakta yang muncul. \\
\hline & Apakah fakta digunakan untuk mengkonstruksi konsep. \\
\hline & Apakah ada proses interpretasi data. \\
\hline & Apakah ada pertanyaan terkait kemunculan suatu prinsip. \\
\hline & Apakah ada pertanyaan terkait analisis. \\
\hline & Apakah kesimpulan dibuat berdasarkan data yang direkam. \\
\hline & Apakah kesimpulan yang dibuat menggambarkan judul/tujuan. \\
\hline
\end{tabular}

\section{HASIL DAN PEMBAHASAN}

Fokus hasil penelitian ini adalah analisis LKS terhadap kesesuaian konseptual, kesesuaian praktikal dan kesesuaian konstruksi pengetahuan.

\section{Hasil analisis terkait konseptual}

Analisis konseptual dilakukan dengan cara menilai kesesuaian setiap parameter dalam instrumen dengan komponen penyusun LKS.

Tabel 2. Hasil analisis terkait konseptual LKS

\begin{tabular}{|c|c|c|c|c|c|c|}
\hline \multirow[t]{2}{*}{ Parameter } & \multicolumn{6}{|c|}{ LKS } \\
\hline & 1 & 2 & 3 & 4 & 5 & 6 \\
\hline Apakah konten sesuai dengan Kompetensis dasar (KD). & Tidak & Tidak & Tidak & Ya & Ya & $\mathrm{Ya}$ \\
\hline $\begin{array}{l}\text { Apakah kompetensi yang dikembangkan LKS sesuai } \\
\text { dengan KD. }\end{array}$ & Tidak & Tidak & Tidak & $\mathrm{Ya}$ & Ya & $\mathrm{Ya}$ \\
\hline $\begin{array}{l}\text { Apakah judul praktikum sesuai dengan langkah-langkah } \\
\text { kerja. }\end{array}$ & Ya & Tidak & $\mathrm{Ya}$ & Tidak & $\mathrm{Ya}$ & Tidak \\
\hline $\begin{array}{l}\text { Apakah tujuan praktikum sesuai dengan langkah-langkah } \\
\text { kerja. }\end{array}$ & Ya & Tidak & $\mathrm{Ya}$ & Tidak & Ya & Tidak \\
\hline $\begin{array}{l}\text { Apakah kegiatan praktikum sesuai dengan tingkat } \\
\text { kognitif siswa SMA. }\end{array}$ & $\mathrm{Ya}$ & $\mathrm{Ya}$ & Ya & Ya & $\mathrm{Ya}$ & $\mathrm{Ya}$ \\
\hline
\end{tabular}


Pada tabel 2, menunjukkan ada beberapa parameter yang tidak sesuai dengan komponen LKS yaitu (1) LKS yang digunakan pada kurikulum 2013 tidak sesuai dengan konten dan kompetensi kompetensi yang dituntut KD. Adapun KD dalam kurikulum yaitu KD 3.8. Mengelompokkan tumbuhan ke dalam divisio berdasarkan ciri-ciri umum, serta mengaitkan peranannya dalam kehidupan dan KD 4.8. Menyajikan laporan hasil pengamatan dan analisis fenetik dan filogenetik tumbuhan serta peranannya dalam kehidupan. LKS hanya mengembangkan kompetensi KD 3.8 saja. Kompetensi dasar diharapkan dapat dicapai melalui pengembangan kegiatan praktikum (Supriatno, 2013). Hasil penelitiaan Hidayat menunjukkan bahwa penugasan analisis fenetik dapat memudahkan siswa memahami ciri-ciri tumbuhan berbiji (Hidayat et al., 2015). Berdasarkan hal tersebut kompetensi KD 4.8 termasuk esensial sehingga harus dimasukkan dalam LKS ; (2) Judul dan tujuan LKS yang dikategorikan tidak sesuai dengan kegiatan dan langkah kerja adalah LKS tidak menuliskan judul dan tujuan. Tiga dari 6 sampel tidak menuliskan judul dan tujuan dalam LKS. Judul dan tujuan praktikum adalah hal yang sangat penting dirumuskan dalam LKS. Salah satu karakteristik utama kerja praktek adalah perumusan tujuan harus jelas (Millar, 2004).Tujuan adalah merupakan capaian yang harus dimiliki siswa sesudah melakukan praktikum. Ketika siswa terlibat dalam membangun pengetahuan perlu dipandu dengan fokus questions (Novak \&Gowin, 1984). Fokus questions yang ada pada judul ataupun tujuan akan memandu siswa merekam data hasil pengamatan peristiwa/objek.

\section{Hasil analisis terkait praktikal}

Penilaian dilakukan dengan cara melihat ketercapaian parameter praktikal dari hasil uji coba langkah langkah kerja yang ada pada LKS.

Tabel 3. Hasil analisis terkait praktikal.

\begin{tabular}{|c|c|c|c|c|c|c|}
\hline \multirow[t]{2}{*}{ Parameter } & \multicolumn{6}{|c|}{ LKS } \\
\hline & 1 & 2 & 3 & 4 & 5 & 6 \\
\hline Apakah alat yang digunakan tersedia disekolah. & $\mathrm{Ya}$ & Ya & Ya & $\mathrm{Ya}$ & $\mathrm{Ya}$ & Ya \\
\hline $\begin{array}{l}\text { Apakah bahan yang digunakan mudah didapat } \\
\text { siswa. }\end{array}$ & Ya & $\mathrm{Ya}$ & Ya & Ya & $\mathrm{Ya}$ & Ya \\
\hline Apakah langkah kerja sudah disusun terstruktur. & Tidak & Tidak & Tidak & Tidak & Tidak & Tidak \\
\hline $\begin{array}{l}\text { Apakah langkah kerja dapat dieksekusi tanpa } \\
\text { kesulitan. }\end{array}$ & $\mathrm{Ya}$ & Ya & $\mathrm{Ya}$ & Ya & $\mathrm{Ya}$ & Ya \\
\hline $\begin{array}{l}\text { Apakah objek/fenomena muncul dalam } \\
\text { pengamatan. }\end{array}$ & Tidak & Tidak & Tidak & Tidak & Tidak & Tidak \\
\hline Apakah objek/fenomena mudah untuk diamati. & Ya & Ya & Ya & Ya & Ya & Ya \\
\hline Apakah ada perekaman data. & Ya & Ya & Ya & Ya & Ya & Ya \\
\hline Bagaimana bentuk perekaman objek/fenomena. & Ya & Ya & Ya & Ya & Ya & Ya \\
\hline $\begin{array}{l}\text { Apakah objek fenomena relevan dengan } \\
\text { judul/tujuan. }\end{array}$ & Ya & Tidak & Tidak & Tidak & Ya & Tidak \\
\hline $\begin{array}{l}\text { Apakah ada alokasi waktu untuk kegiatan } \\
\text { praktikum. }\end{array}$ & Tidak & Tidak & Tidak & Tidak & Tidak & Tidak \\
\hline Apakah ada petunjuk safety lab. & Tidak & Tidak & Tidak & Tidak & Tidak & Tidak \\
\hline Apakah prosedur petunjuk safety labnya tepat. & Tidak & Tidak & Tidak & Tidak & Tidak & Tidak \\
\hline
\end{tabular}


Pada tabel 3, Ada beberapa parameneter yang tidak ada dalam LKS yaitu (1)Parameter apakah langkah-langkah praktikum disusun terstruktur, keenam LKS sampel tidak memiliki langkah-langkah yang terstruktur. Pada langkah kerja tidak dijelaskan dengan rinci bagaimana cara mengamati setiap objek praktikum, bagianbagian apa saja dari objek yang harus diamati dan apa saja yang harus direkam dalam bentuk gambar atau yang dideskripsikan ke dalam tabel hasil pengamatan. Contoh langkah kerja yang tidak terstruktur yaitu gambarlah strobilus tumbuhan pinus, keluarkan biji yang terdapat pada strobilus betina kemudian gambarlah hasil pengamatanmu. Langkah kerja ini tidak dapat membimbing siswa untuk mengidentifikasi bagaimana letak biji pada tumbuhan pinus, sehingga siswa tidak dapat merekam data yang seharusnya diperlukan untuk pemahaman konsep di akhir kegiatan praktikum. Langkah-langkah kerja haruslah dideskripsikan dengan baik (Abrahams \& Millar, 2008). Susunan langkah-langkah kerja sangat menentukan apa yang seharusnya dilakukan siswa pada kegiatan praktikum; (2) parameter munculnya objek/fenomena, keenam LKS sampel tidak memfasilitasi munculnya objek/ fenomena dengan jelas. Munculnya objek/ fenomena sangat erat kaitannya dengan langkah kerja. Karena langkah kerja tidak terstruktur dengan rinci maka data yang dicatat tidak sesuai dengan yang diinginkan untuk menjawab tujuan praktikum; (3)parameter objek/fenomena relevan dengan judul/tujuan. Hannya satu LKS yang memenuhi parameter ini karena lima LKS lainnya tidak menuliskan judul/tujuan; (4)parameter kesesuaian alokasi waktu. Keenam LKS tidak sesuai karena tidak ada LKS yang mencantumkan alokasi waktu; (5) parameter petunjuk safety lab. Keenam LKS tidak ada yang memuat safety lab. Temuan ini sejalan dengan penelitian sebelumnya oleh Supriatno (2013) yang menyatakan banyaknya permasalahan praktikum karena langkah-langkah kerja yang tidak terstruktur sehingga siswa tidak dapat berinteraksi dengan objek/fenomena relevan.

\section{Hasil analisis terkait konstruksi pengetahuan}

Penilaian dilakukan dengan cara mencoba menjawab pertanyaan pada LKS. Hasilnya dapat dilihat pada table 4.

Tabel 4. Hasil analisis terkait konstruksi pengetahuan.

\begin{tabular}{|c|c|c|c|c|c|c|}
\hline \multirow[t]{2}{*}{ Parameter } & \multicolumn{6}{|c|}{ LKS } \\
\hline & 1 & 2 & 3 & 4 & 5 & 6 \\
\hline $\begin{array}{l}\text { Apakah pertanyaan praktikum tidak dapat dijawab } \\
\text { tanpa praktikum. }\end{array}$ & ya & ya & Tidak & ya & ya & ya \\
\hline $\begin{array}{l}\text { Apakah pertanyaan praktikum menanyakan karakter } \\
\text { fakta yang muncul. }\end{array}$ & Ya & Ya & Tidak & Tidak & $\mathrm{Ya}$ & Tidak \\
\hline $\begin{array}{l}\text { Apakah fakta digunakan untuk mengkonstruksi } \\
\text { konsep. }\end{array}$ & $\mathrm{Ya}$ & Tidak & Tidak & Tidak & $\mathrm{Ya}$ & $\mathrm{Ya}$ \\
\hline Apakah ada proses interpretasi data. & Ya & Tidak & Tidak & Tidak & Ya & $\mathrm{Ya}$ \\
\hline $\begin{array}{l}\text { Apakah ada pertanyaan terkait kemunculan suatu } \\
\text { prinsip. }\end{array}$ & Tidak & Tidak & Tidak & Tidak & Tidak & Tidak \\
\hline Apakah ada pertanyaan terkait analisis. & Tidak & Tidak & Tidak & Tidak & Tidak & Tidak \\
\hline $\begin{array}{l}\text { Apakah kesimpulan dibuat berdasarkan data yang } \\
\text { direkam. }\end{array}$ & $\mathrm{Ya}$ & Tidak & Tidak & Tidak & $\mathrm{Ya}$ & Tidak \\
\hline $\begin{array}{l}\text { Apakah kesimpulan yang dibuat menggambarkan } \\
\text { judul/tujuan. }\end{array}$ & $\mathrm{Ya}$ & Tidak & Tidak & Tidak & $\mathrm{Ya}$ & Tidak \\
\hline
\end{tabular}


Pada tabel 4, Ada beberapa parameter yang tidak ada dalam LKS yaitu:(1) tidak adanya pertanyaan terkait munculnya suatu prinsip; (2) tidak ada pertanyaan analisis; (3) Secara umum kesimpulan tidak dibuat dari data hasil pengamatan. Temuan ini selaras dengan hasil penelitian (Wulandari \& Melati, 2013)menyataan bahwa siswa kurang tepat dalam membuat kesimpulan dimana kesimpulan tidak sesuai dengan tujuan percobaan dan masih terdapat kesalahan konsep. Pertanyaan yang dikembangkan dalam LKS berfungsi untuk membantu siswa menghubungkan fakta yang ditemui dengan konsep pengetahuan baru yang dibagun dari hasil praktikum, sehingga siswa dapat menyusun kesimpulan dengan benar. Tujuan tugas praktis dapat meningkatkan pengetahuan ilmiah yaitu membantu siswa menghubungkan domain real dengan domain ideas (Millar, 2004).

Secara keseluruhan hasil analis komponen-komponen LKS dalam bentuk persentase dapat dilihat dalam tabel 5 .

Tabel 5. Persentase kesesuaian LKS dengan parameter instrumen.

\begin{tabular}{lllllll}
\hline & Parameter & \multicolumn{5}{c}{ Kesesuaian LKS dengan parameter instrumen } \\
\cline { 2 - 7 } & 1 & 2 & 3 & 4 & 5 & 6 \\
\hline Analisis Konseptual & $3 / 5$ & $1 / 5$ & $3 / 25$ & $3 / 5$ & $5 / 5$ & $3 / 5$ \\
\hline Analisis Praktikal & $7 / 12$ & $6 / 12$ & $7 / 12$ & $7 / 12$ & $7 / 12$ & $6 / 12$ \\
\hline Analisis konstruksi pengetahuan & $6 / 8$ & $2 / 8$ & $0 / 8$ & $1 / 8$ & $6 / 8$ & $3 / 8$ \\
\hline Jumlah & $16 / 25$ & $9 / 25$ & $10 / 25$ & $11 / 25$ & $18 / 25$ & $12 / 25$ \\
\hline Persentase & $64 \%$ & $36 \%$ & $40 \%$ & $44 \%$ & $72 \%$ & $48 \%$ \\
\hline
\end{tabular}

Pada tabel 5, menunjukkan bahwa kesesuaian LKS KTSP dengan parameter yang tertinggi adalalah 72\%, sedangkan kesesuaian LKS Kurikulum 2013 adalah 64\%. Perbedaan ini dikarenakan jumlah kesesuaian LKS KTSP pada aspek konseptual lebih tinggi dibandingkan dengan Kurikulum 2013, hal ini mengisyaratkan bahwa LKS yang dipakai tidak disesuaikan dengan perubahan tuntutan KD seiring perubahan kurikulum. Secara keseluruhan kesesuaian LKS dengan instrumen masih digolongkan rendah sehingga LKS yang dipakai disekolah masih perlu direkonstruksi agar kegiatan praktikum lebih berarti.

\section{LKS Hasil Rekonstruksi}

Setelah dilakukan analisis terkait konseptual prosedural dan konstruksi pengetahuan, maka peneliti mencoba menyusun LKS untuk materi spermatophyta menggunakan analisis fenetik. Rekonstruksi ini bertujuan agar lebih sesuai secara konseptual, prosedural san konstruksi pengetahuan untuk siswa SMA. 


\section{LKS HASIL REKONTRUKSI}

A. JUDUL : Bagaimana mengelompokkan dan membuat fenogram divisio spermatophyta?

B. ALOKASI WAKTU : 3 X 45 Menit /(3JP)

\section{TUJUAN PRAKTIKUM:}

1. Melalui pengamatan siswa dapat mengidentifikasi ciri-ciri morfologi daun tumbuhan berbiji (Spermatophyta).

2. Melalui pengamatan siswa dapat mengidentifikasi ciri-ciri morfologi batang tumbuhan berbiji (Spermatophyta).

3. Melalui pengamatan siswa dapat mengidentifikasi ciri-ciri morfologi akar tumbuhan berbiji (Spermatophyta).

4. Melalui pengamatan siswa dapat mengidentifikasi ciri-ciri morfologi bunga/strobilus tumbuhan berbiji (Spermatophyta).

5. Melalui pengamatan siswa dapat mengidentifikasi letak biji tumbuhan berbiji (Spermatophyta).

6. Melalui pengamatan siswa dapat mengidentifikasi ciri-ciri biji tumbuhan berbiji (Spermatophyta).

7. Melalui hasil identifikasi letak biji siswa dapat mengelompokkan tumbuhan berbiji (Spermatophyta).

8. Melalui hasil identifikasi morfologi akar, batang, daun, bunga, biji siswa dapat mengelompokkan tumbuhan berbiji (Spermatophyta).

9. Melalui data hasil pengamatan karakteristik masing-masing spesies siswa dapat membuat fenogram divisio spermatophyta.

\section{ALAT DAN BAHAN:}

a. ALAT: Lup dan cuter/pisau

b. BAHAN: Bagian tubuh tanaman ( akar, batang,daun,bunga/srobilus, buah dan biji) dari tumbuhan pinus, melinjo, mangga, palem yang tumbuh dilingkungan tempat tinggal siswa.

\section{E. CARA KERJA :}

Langkah- langkah kerja Kegiatan 1

1. Ambillah daun dari setiap objek tanaman, lalu amati dan identifikasi dengan cermat kemudian gambarlah pertulangan daun dan catat hasil identifikasi pada hasil pengamatan.

2. Ambillah batang dari setiap objek tanaman, lalu amati dan identifikasi permukaan dan percabangannya dengan cermat kemudian catat dan gambarlah hasil identifikasi pada tabel hasil pengamatan.

3. Ambillah akar dari setiap objek tanaman, lalu amati dan identifikasi dengan cermat bagaimana sistem perakarannya kemudian catat dan gambarlah hasil identifikasi pada tabel hasil pengamatan.

4. Ambillah bunga atau stobilus dari setiap objek tanaman, lalu amati dan identifikasi dengan cermat kemudian catat dan gambarlah bagian bagiannya pada tabel hasil pengamatan.

5. Pisahkanlah satu bagian sisik stobilus betina dengan menggunakan pisau secara hati-hati, kemudian amati letak biji, catat dan gambarlah letak biji pada sisik (daun buah) dan hasil identifikasi pada tabel hasil pengamatan.

6. Ambillah bunga dari setiap objek tanaman, dan belahlah bunga tersebut dengan pisau sehingga terlihat bagian bagian-bagiannya, catat dan gambarlah bagian tangkai putik, kepala putik, bakal buah, dan bakal biji.

7. Ambillah biji dari setiap objek tanaman, lalu amati dan identifikasi keping bijinya kemudian catat dan gambarlah hasilnya pada tabel hasil pengamatan. 


\section{F. TABEL HASIL PENGAMATAN}

a. Tabel Gambar Hasil Pengamatan

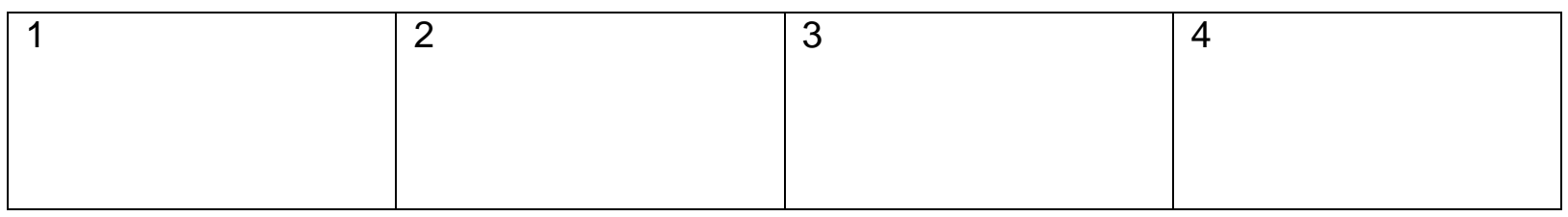

b. Hasil Identifikasi

\begin{tabular}{|l|l|l|l|l|l|l|l|l|}
\hline No & $\begin{array}{l}\text { Nama } \\
\text { Tumbuhan }\end{array}$ & $\begin{array}{l}\text { Bentuk Daun } \\
\text { dan } \\
\text { pertulangan } \\
\text { daun }\end{array}$ & $\begin{array}{l}\text { Bentuk dan } \\
\text { Percabangan } \\
\text { Batang }\end{array}$ & $\begin{array}{l}\text { Sistem } \\
\text { perakaran } \\
\text { Akar }\end{array}$ & $\begin{array}{l}\text { Jumlah } \\
\text { mahkota }\end{array}$ & $\begin{array}{l}\text { Jumlah } \\
\text { kelopak } \\
\text { bungan }\end{array}$ & $\begin{array}{l}\text { Letak } \\
\text { Biji }\end{array}$ & $\begin{array}{l}\text { Jumlah } \\
\text { keping } \\
\text { biji }\end{array}$ \\
\hline 1 & & & & & & & & \\
\hline 2 & & & & & & & & \\
\hline 3 & & & & & & & & \\
\hline 4 & & & & & & & & \\
\hline
\end{tabular}

Pertanyaan:

1. Tumbuhan apa saja yang memiliki persamaan?

2. Tumbuhan apa saja yang dapat dijadikan dalam kelompok yang sama?

3. Apa yang menjadi dasar pengelompokan tumbuhan pada soal no 2 ?

Langkah- Langakah kerja Kegiatan 2:

1. Tentukanlah unit-unit taksonomi operasional (OTU) yang akan dikaji (Spesies tumbuhan yang akan dikaji)

2. Pilihlah karakter yang dimiliki/ tidak oleh setiap spesies, dan memilih karakter yang dominan.

3. Berikan simbol (1) untuk karakter tanaman yang dimiliki, simbol (0) untuk karakter tanaman yang tidak dimiliki.

4. Buatlah matrik kesamaan dengan menhubungkan (1/0) yang sama.

5. Lakukan clustering, diurutkan dari tanaman yang memiliki angka kesamaan tertinggi hingga terkecil

6. Buatlah fenogram.

Hasil kajian:

1. Tuliskan spesies yang diidentifikasi pada langkah kerja 1

\begin{tabular}{|l|l|l|}
\hline No. & Nama Spesies & Simbol spesies \\
\hline 1 & & A \\
\hline 2 & & B \\
\hline 3 & & C \\
\hline 4 & & D \\
\hline
\end{tabular}

2. Pilih karakter dominan yang yang dimiliki atau yang tidak dimiliki setiap spesies.

\begin{tabular}{|l|l|l|}
\hline No. & Organ & Karakter \\
\hline 1 & Batang & \\
\hline 2 & Daun & \\
\hline 3 & Akar & \\
\hline 4 & Bunga & \\
\hline
\end{tabular}

\section{Sisri, dkk}


\begin{tabular}{|l|l|}
\hline 5 & Biji \\
\hline
\end{tabular}

3. Isilah tabel berikut dengan tanda (1) jika spesies memiliki karakter tersebut dan (0) jika spesies tersebut tidak memiliki karakter tersebut.

\begin{tabular}{|l|l|l|l|l|l|}
\hline No. & Karakter & A & B & C & D \\
\hline 1 & & & & & \\
\hline 2 & & & & & \\
\hline 3 & & & & & \\
\hline 4 & & & & & \\
\hline 5 & & & & & \\
\hline 6 & & & & & \\
\hline
\end{tabular}

4. Isilah Tabel Matrik kesamaan dibawah ini dengan simbol (1)/(0) untuk menghitung koefisien kesamaan.

\begin{tabular}{|c|c|c|c|c|c|}
\hline Spesies & 1 & 2 & 3 & 4 & 5 \\
\hline$A$ & & & & & \\
\hline$B$ & & & & & \\
\hline C & & & & & \\
\hline $\mathrm{D}$ & & & & & \\
\hline
\end{tabular}

Koefisien kesamaan dapat dihutung dengan rumus berikut:

$A B=$ Jumlah karakter $A$ yang sama dengan $B / 5=$

$A C=$ Jumlah karakter $A$ yang sama dengan $C / 5=$

$A D=$ Jumlah karakter $A$ yang sama dengan $D / 5=$

$\mathrm{BC}=$ Jumlah karakter $\mathrm{B}$ yang sama dengan $\mathrm{C} / 5=$

$\mathrm{BD}=$ Jumlah karakter $\mathrm{B}$ yang sama dengan $\mathrm{D} / 5=$

$\mathrm{CD}=$ Jumlah karakter $\mathrm{C}$ yang sama dengan $\mathrm{D} / 5=$

Isikalah tabel dibawah ini dengan hasil perhitungan koofesien kesamaan.

\begin{tabular}{|l|l|l|l|l|}
\hline & A & B & C & D \\
\hline A & 1 & & & \\
\hline B & & 1 & & \\
\hline C & & & 1 & \\
\hline D & & & & 1 \\
\hline
\end{tabular}

5. Lakukan clustering.

6. Buatlah fenogram dengan ketentuan sumbu $Y$ nilai kooefisien kesamaan dan sumbu $X$ untuk spesies.

\begin{tabular}{|l|l|l|l|l|l|l|l|l|l|l|l|}
\hline & & & & & & & & & & & \\
\hline & & & & & & & & & & & \\
\hline & & & & & & & & & & & \\
\hline & & & & & & & & & & & \\
\hline & & & & & & & & & & & \\
\hline & & & & & & & & & & & \\
\hline & & & & & & & & & & & \\
\hline & & & & & & & & & & & \\
\hline & & & & & & & & & & & \\
\hline & & & & & & & & & & & \\
\hline & & & & & & & & & & & \\
\hline
\end{tabular}


Pertanyaan:

1. Dari fenogram di atas spesies manakah yang berkerabat dekat?

2. Dari fenogram ada berapa kelompok spesies yang dikaji?

H.KESIMPULAN.

\section{KESIMPULAN}

Berdasarkan hasil analisis terhadap petunjuk praktikum (LKS) tentang spermatophyta ditemukan adanya beberapa permasalahan, baik dari segi kesesuaian konten LKS, kesesuaian praktikal dan kesesuaian kegunaannya sebagai media konstruksi pengetahuan. Angka perbandingan persentase kesesuaian LKS berbasis Kurikulum 2013 lebih rendah dari pada LKS berbasis KTSP. Hal ini disebabkan LKS yang digunakan pada kurikulum 2013 tidak mengalami perubahan sejalan dengan perkembangan kurikulum. Dengan demikian perlu rekonstruksi LKS materi spermatophyta agar kegiatan praktikum lebih berarti. Saran untuk penelitian ini adalah perlunya penelitian jangka panjang terkait kemampuan guru biologi mengembangkan LKS untuk mengasah kemampuan prosedural dan konstruksi pengetahuan siswa melalui kegiatan praktikum.

\section{DAFTAR PUSTAKA}

Abdel-Hameed, U. K., Tantawy, M. E., Salim, M. A., Mourad, M. M., \& Ishak, I. F. (2015). Phenetic Analysis of Morphological and Molecular Traits in Acanthaceae Juss. Journal of Biosciences and Medicines, 03(03), 18-34. https://doi.org/10.4236/jbm.2015.33004

Abrahams, I., \& Millar, R. (2008). Does practical work really work? A study of the effectiveness of practical work as a teaching and learning method in school science. International Journal of Science Education, 30(14), 1945-1969. https://doi.org/10.1080/09500690701749305

Aisya, N. S. M., SaefudinSupriatno, B., \& Anggraeni, S. (2016). Penerapan Diagram Vee dalam Model Pembelajaran Inquiry Lab dan Group Investigation untuk Meningkatkan Kemampuan Literasi Kuantitatif Siswa Kelas VII pada Materi Pencemaran Lingkungan Application of Vee Diagram Learning Strategy Through Inquiry Lab and Gro. Proceeding Biology Education Conference, 13(1), 112117.

Fathurrohim,(2016) PENGGUNAAN ANALISIS FENETIK UNTUK MENGUNGKAP KONSEPSI SISWA PADA KONSEP KLASIFIKASI TUMBUHAN BERBIJI Universitas Pendidikan Indonesia / repository.upi.edu / perpustakaan.upi.edu.

Astuti, T. (2015). Manajemen praktikum pembelajaran ipa. Manajemen Pendidikan, 9(1), 57-64. e-mail: hilariaastuti@yahoo.co.id

Educatuon, L. (2010). Does practical work work? A study of the effectiveness of practical work as a teaching and learning method in school science. 1-35.

Hidayat, T., Sutarno, N., \& Awaliyah, R. N. (2015). Pengaruh Penugasan Fenetik Terhadap Penguasaan Konsep Keanekaragaman Tumbuhan Biji. Jurnal Pengajaran Matematika Dan IImu Pengetahuan Alam, 17(2), 209. https://doi.org/10.18269/jpmipa.v17i2.247

\section{Sisri, dkk}


Hidayat, T. (2017). Menggairahkan pembelajaran taksonomi di kelas menggunakan metode fenetik. February.

Kemendikbud. (2016). Permendikbud 24 tahun 2016 tentang Kompetensi Inti dan Kompetensi Dasar Pelajaran pada Kurikulum 2013. Jakarta, 1, 5.

Millar, R. (2004). The role of practical work in the teaching and learning of science. October.

Millar, R., \& Abrahams, I. (2009). Practical work - Research Database, The University of York. School Science Review, 91(334), vol 91, no. 334, pp. 59-64. https://doi.org/10.1007/978-3-319-07857-1_2

Niteni, N. (2020). NEED ANALYSIS FOR E-BOOK OF PRACTICUM INSTRUCTIONS BASED ON TRI NEED ANALYSIS FOR E-BOOK OF PRACTICUM INSTRUCTIONS BASED ON TRI N ( NITENI, NIROKKE, NAMBAHI ). January.

Rustaman, N. R. dan A. R. (2003). Kemampuan Kerja Ilmiah dalam Sains (Karakteristik Kurikulum Berbasis Kompetensi Mata Pelajaran Biologi. Upi, 3-3. https://doi.org/10.4103/0019-5413.93682

Rustaman, N. Y. (2005). PERKEMBANGAN PENELITIAN PEMBELAJARAN INKUIRI DALAM PENDIDIKAN SAINS Development of Research in Inquiry Science Teaching. Seminar Nasional II, 22-23.

Sani, S. S. (2014). Teachers' Purposes and Practices in Implementing Practical Work at the Lower Secondary School Level. Procedia - Social and Behavioral Sciences, 116(1996), 1016-1020. https://doi.org/10.1016/j.sbspro.2014.01.338

Sadikin, A., \& Hakim, N. (2015). Program Studi Pendidikan Biologi. 163-174.

Supriatno, B. (2013). Pengembangan Program Perkuliahan Pengembangan Praktikum Biologi Sekolah Berbasis ANCORB untuk Mengembangkan Kemampuan Merancang dan Mengembangkan Desain Kegiatan Laboratorium. http://repository.upi.edu/id/eprint/3661

Supriatno, B., \& Si, M. (2018). Praktikum untuk Membangun Kompetensi. 15, 1-18.

The Society for Biology. (2010). The Importance of Practical Biology: from School to Higher Education. 44(277981).

Wulandari, R., \& Melati, H. (2013). Analisis Keterampilan Komunikasi Dalam Penyusunan Laporan Praktikum Termokimia Pada Siswa Kelas Xi Ipa. Jurnal Pendidikan Dan Pembelajaran Untan, 2(5), 1-13.

Yılmaz, İ., \& Yalçın, N. (2012). The relationship of procedural and declarative knowledge of science teacher candidates in Newton's laws of motion to understanding. American International Journal of Contemporary Research, 2(3), 50-56.

Yuniastuti,E., (2013).Peningkatan keterampilan proses,motivasi, dan hasil belajar biologi dengan strategi pembelajaran inkuiri terbimbing pada siswa kelas VII SMP Kartika V-1 Balikpapan.Jurnal Penelitian Pendidikan Vol. 14 No. 1, Hal.79 